\title{
Observation of Flow and Discharge through Multi Gating System
}

\author{
I.Rajkumar, N.Rajini, M.Jeeva, K.Arunkumar, M.Jeeva, P.Kaliraj
}

\begin{abstract}
In the case of transport industries, engineering products made by the method of casting as a traditional. it is an effective design of the feeding system. To address the bizarre of gating system by experimental investigations: Centre Sprue Parallel Connection (CSPC) and Centre Spure Runner Extension Parallel Connection (CS-RE-PC). By using water medium to analyse velocity and discharge. Congest result can be applicable to any one metal which is a like kinematic viscosity of water. By shutting disguised gates were enlist data in a various time. due to the equidistant arrangement, a uniform flow throughout the cavity. Almost in all the cases, the higher or equal deport was found in gating design CS-RE-PC and useful to improve optimum runner and find the gate in the multi- cavity system.
\end{abstract}

Keywords : Casting, Discharge, and Mould

\section{INTRODUCTION}

$\mathrm{M}$ etal casting process is defined as characterized a role as liquid metal alter into metal item relying on the mould cavity Three approaches - The experiment constitutes empirical relations, Hydraulics based on Bernoulli's and continuity equation, and the conversion of mass and momentum involved by numerical simulation, followed by casting industry.

The flow behaviours is performed by using water in transparent mould on a multi-gating system. it creates the module with preferred geometry shown in Fig.1. The requirement of automobile, industrial and domestic components production. casting process includes in scientific, experiential setup and general Fluid mechanics. The system of melting the metals, feeding system, cavity formation, pouring the molten metal leads to solidifications. The gate arrangement changes from farthest to near cavity [1], far among two gates was observed. [2,4,5] Indicates the ratio of metal flow based on dimensionless and independent

Revised Manuscript Received on December 5, 2019

I.Rakumar*, Department of Mechanical Engineering Kalasalinagm Academy of Research and Education, Krishnankoil, Virudhunagar, Tamil Nadu, India. Email: irajkumarilango@gmail.com

N.Rajini, Department of Mechanical Engineering, Kalasalinagm Academy of Research and Education, Krishnankoil, Virudhunagar, Tamil Nadu, India. Email: rajiniklu@ gmail.com

M.Jeeva, K.Arunkumar, P.Kaliraj, Department of Mechanical Engineering, Kalasalinagm Academy of Research and Education, Krishnankoil, Virudhunagar, Tamil Nadu, India. Email: 9915009074@klu.ac.in of gate distances. The discharge is maximum in the gate farther to sprue and minimum from farther to nearer gates [3]. If defeat occur leads to entire casting become fail. Alternative processes included in casting, made it arduous to yield the proper response to concoct entire process, a effective one. The filling of mould is significant in casting process. The characteristics flow changes with discrete material. [6] Water's kinematic viscosity similar aluminium and copper, So Aluminum behaves high or less closely to the water. The control volume of hydraulic-based model process find by gating system for nonlinear optimization [7]. The comparison between the outcome of feeding system with water modelling, simulation and a correspondence of flow [8]. According to the researchers [9], In a Shut duct, the velocity of the aluminium act like water in a turbulent manner. The researchers [10] as same as cast iron. Also, the molten metal flow into basin was noticed by Wallace[11].

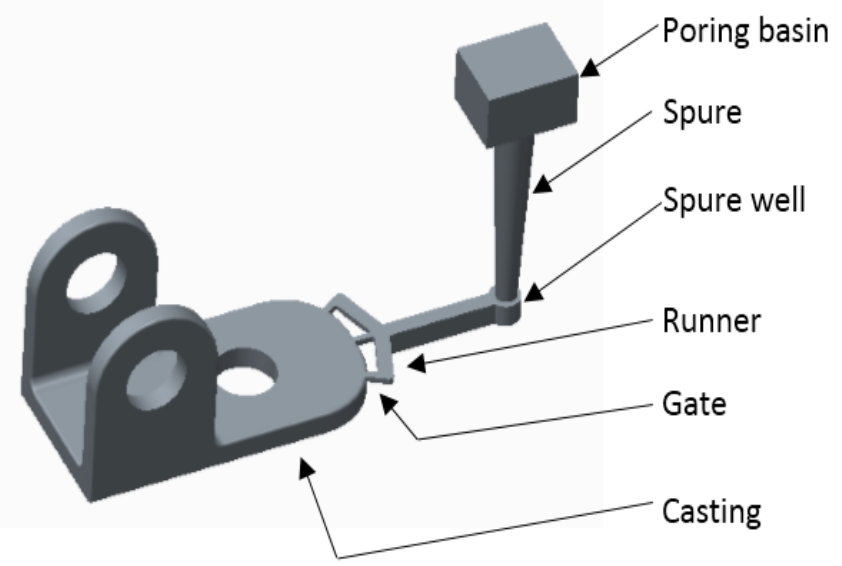

Fig. 1. Casting component in a typical gating design.

The researcher [11] as same as cast iron. molten metal flow in the basin studied by The researcher [12]. Flow of molten metal based on the dimension, location and the far amidst gate arrangements to have the high efficiency. By the viscosity, surface tension and density is characterise the flow of the metal fluid. It helps to avoid any shortcoming leads to rise the quality of the product. due to the disturbance in the metal flow, cavity filling and various misalignments can cause defects. the best way to orginate gate formation leads to increase an insight of the materialized. Thus the flow based on the distance from one gate to another gate, location, dimension and the and efficiency. The splendid of gate formation by increase the insight of the casting [13].

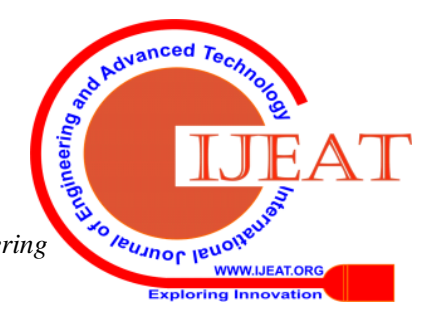




\section{Observation of Flow and Discharge through Multi Gating System}

Metal flow through the multi-gating system With use of horizontal gate and vertical sprue arrangement. In this method, speed of metal from farthest gate twice to near gate i.e be $50 \%$ more flow from nearer sprue [14]. The efficiency

which settle the flow into the cavity, depends upon the gate formation. Throughout the product By re-assembling of gate, distribution in cavity, and the molten metal shows even velocity. little scale ventures advance for a mass production, struggle to find an optimum runner gate. Mass production application in some previous experimental study compared to parallel connection setup has even and optimum results. So parallel system is beneficial for little scale ventures.

\section{GEOMETRIC MODEL}

The readings of two set of model are shown in the Fig.2. Tabulated by different gates shut at a time in center spure parallel connection and runner extension of center spure parallel connection. Pouring basin defined as direct contact of molten into a place is known. Spure is known passage through metal reaches the gate. To increase the velocity by converging the sprue. through the runner molten metal attain the gates.
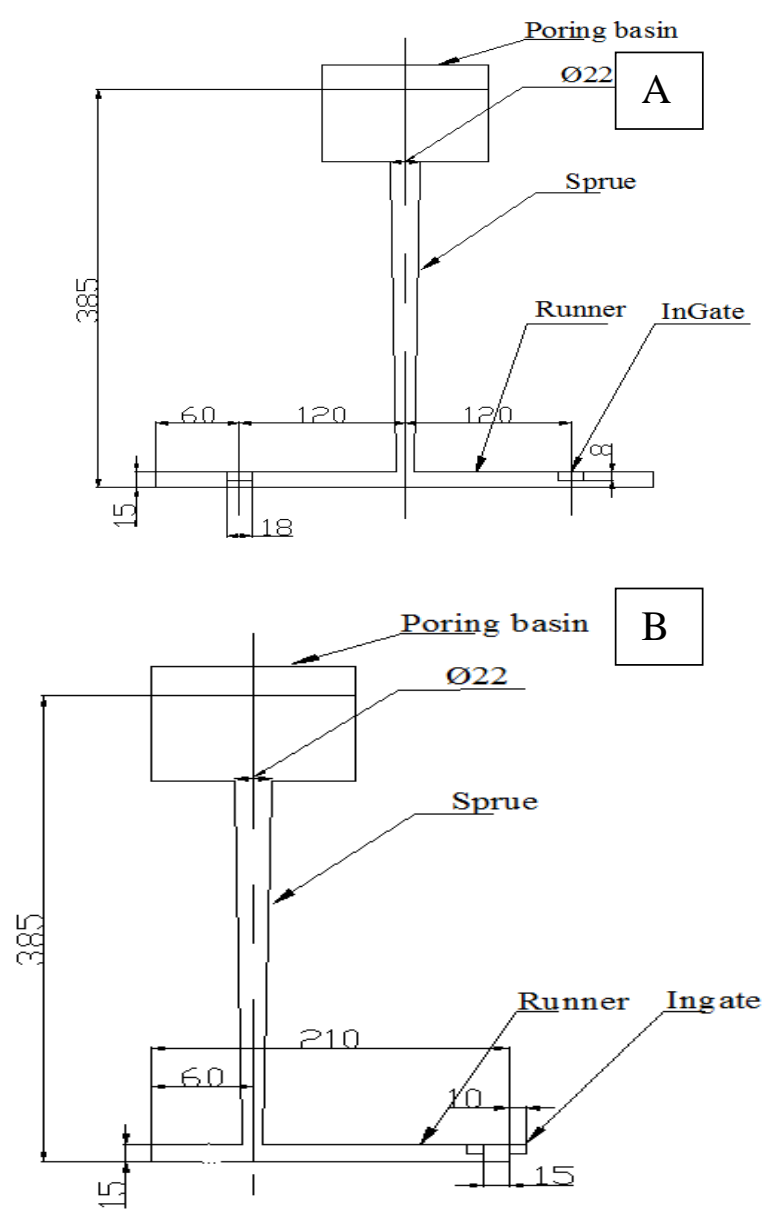

Fig. 2. Water mold design (A)CSPC and (B) CS-RE-PC.
The experiments was designed based on $1: 2: 1.5$. based on order of gates, the 2 set-up is prepared. The $1^{\text {st }}$ setup of sprue set as center of parallel gate order, the uniform distance in between the gates and sprue. The $2^{\text {nd }}$ set-up involve of sprue is farthest center position in parallel gate as shown in the Fig.3. The each setup contains 11 experiments in different combination, by closing or opening the specific gates.

The flow of water is in constant head into the pouring basin. During the flow better visibility added colour through a vessel of the constant cross section to quantity of the liquid. The total time estimate by filling the water about $500 \mathrm{~cm} 3$ volume through pouring basin. Conducted the experiment in more than a few times, and the readings are taken on an average basis.

Table-I. Results of two different mould setup.

\begin{tabular}{|c|c|c|c|c|c|c|c|c|c|c|}
\hline \multirow{2}{*}{$\begin{array}{l}\text { Ex. } \\
\text { No }\end{array}$} & \multicolumn{4}{|c|}{$\begin{array}{c}\text { CSPC Volume through } \\
\text { gates }\left(\mathrm{cm}^{3}\right)\end{array}$} & \multirow{2}{*}{$\begin{array}{c}\mathrm{T} \\
\sec \end{array}$} & \multicolumn{4}{|c|}{$\begin{array}{l}\text { CS-RE-PC Volume } \\
\text { through gates }\left(\mathrm{cm}^{3}\right)\end{array}$} & \multirow[t]{2}{*}{ T sec } \\
\hline & G1 & G2 & G3 & G4 & & G1 & G2 & G3 & G4 & \\
\hline 1 & 125 & 128 & 120 & 127 & 2.73 & 125 & 128 & 120 & 127 & 2.85 \\
\hline 2 & $\mathrm{C}$ & 170 & 163 & 167 & 3.11 & $\mathrm{C}$ & 170 & 163 & 167 & 3.37 \\
\hline 3 & 167 & $\bar{C}$ & 172 & 161 & 2.93 & 167 & $\mathrm{C}$ & 172 & 161 & 3.21 \\
\hline 4 & 170 & 167 & $\mathrm{C}$ & 163 & 2.92 & 170 & 167 & $\mathrm{C}$ & 163 & 3.12 \\
\hline 5 & 165 & 162 & 171 & $\mathrm{C}$ & 2.9 & 165 & 162 & 171 & $\mathrm{C}$ & 2.9 \\
\hline 6 & $\mathrm{C}$ & 255 & 245 & $\mathrm{C}$ & 3.3 & $\mathrm{C}$ & 255 & 245 & $\mathrm{C}$ & 3.76 \\
\hline 7 & 246 & $\bar{C}$ & $\mathrm{C}$ & 254 & 3.22 & 246 & $\mathrm{C}$ & $\mathrm{C}$ & 254 & 3.32 \\
\hline 8 & $\mathrm{C}$ & 245 & $\mathrm{C}$ & 255 & 3.21 & $\mathrm{C}$ & 245 & $\mathrm{C}$ & 255 & 3.36 \\
\hline 9 & 253 & $\mathrm{C}$ & 247 & $\mathrm{C}$ & 3.12 & 253 & $\mathrm{C}$ & 247 & $\mathrm{C}$ & 3.21 \\
\hline 10 & 500 & $\mathrm{C}$ & $\mathrm{C}$ & $\mathrm{C}$ & 5.21 & 500 & $\mathrm{C}$ & $\mathrm{C}$ & $\mathrm{C}$ & 5.3 \\
\hline 11 & $\mathrm{C}$ & $\mathrm{C}$ & $\mathrm{C}$ & 500 & \begin{tabular}{|l|}
5.31 \\
\end{tabular} & $\mathrm{C}$ & $\mathrm{C}$ & $\mathrm{C}$ & 500 & 5.12 \\
\hline
\end{tabular}

Note: C- closed

The table. 1 estimate the first and second setup of eleven experiments by closing a gate with remaining open. The $11^{\text {th }}$ reading are done by closing any one of the gate, 2 gate and 3 gate to determine a data flow through the rest. To comprehend the flow of water through different with a specific separation and time taken to arrive at gate.

\section{RESULTS AND DISCUSSIONS}

The first readings are attained when all the gate open shown in Table. 1. At the time, the readings from the 1 and 2 gates nearly same as set directly opposite to each other, alike to 3 and 4 gates. The time variation less to reach the last two gates Because not as farthest in the set-up provided by [14], even flow through all four gates. Refer the further readings by shutting any one of the gates in the experiments 2, 3, 4 and 5, 
to obtained the time variation compared to previous experiments. Therefore the amplify the velocity of liquid due to. It leads to rise in volume flow through 3 and 4 gates thrice the volume in the 1 and 2 gates

Table-II Comparative discharges of CSPC and CS-RE-PC

\begin{tabular}{|c|c|c|c|c|c|c|c|c|}
\hline \multirow{2}{*}{$\begin{array}{l}\text { Ex. } \\
\text { No. }\end{array}$} & \multicolumn{4}{|c|}{$\begin{array}{l}\text { CSPC setup discharge through } \\
\text { different gates }\left(\mathrm{cm}^{3} / \mathrm{s}\right)\end{array}$} & \multicolumn{4}{|c|}{$\begin{array}{c}\text { CS-RE-PC setup discharge } \\
\text { through different gates } \\
\left(\mathrm{cm}^{3} / \mathrm{s}\right)\end{array}$} \\
\hline & G1 & G2 & G3 & G4 & G1 & G2 & G3 & G4 \\
\hline 1. & 45.79 & 46.89 & 43.96 & 46.52 & 43.86 & 43.51 & 43.86 & 43.86 \\
\hline 2. & C & 54.66 & 52.41 & 53.70 & C & 49.55 & 49.55 & 49.26 \\
\hline 3. & 57.00 & $\mathrm{C}$ & 58.70 & 54.95 & 52.02 & $\mathrm{C}$ & 51.71 & 52.02 \\
\hline 4. & 58.22 & 57.19 & $\mathrm{C}$ & 55.82 & 53.53 & 53.21 & $\mathrm{C}$ & 53.53 \\
\hline 5. & 56.90 & 55.86 & 58.97 & C & 57.59 & 57.24 & 57.59 & C \\
\hline 6. & $\mathrm{C}$ & 77.27 & 74.24 & $\mathrm{C}$ & $\mathrm{C}$ & 66.22 & 66.76 & $\mathrm{C}$ \\
\hline 7. & 76.40 & C & C & 78.88 & 75.30 & C & $\mathrm{C}$ & 75.30 \\
\hline 8. & C & 76.32 & C & 79.44 & C & 74.70 & C & 74.11 \\
\hline 9. & 81.09 & $\mathrm{C}$ & 79.17 & $\mathrm{C}$ & 77.57 & $\mathrm{C}$ & 78.19 & $\mathrm{C}$ \\
\hline 10. & 95.97 & $\mathrm{C}$ & $\mathrm{C}$ & $\mathrm{C}$ & 94.34 & $\mathrm{C}$ & $\mathrm{C}$ & $\mathrm{C}$ \\
\hline 11. & $\mathrm{C}$ & $\mathrm{C}$ & $\mathrm{C}$ & 94.16 & $\mathrm{C}$ & $\mathrm{C}$ & $\mathrm{C}$ & 97.66 \\
\hline
\end{tabular}

The Ex. No.2 displays that the first gate Shut, increases in flow velocity and thus the volume in maximum. From the experiment 6 , the 2 gates are Shut. Better in time and flow residual 2 gates. when the first two gates is Shut, the water takes time to touch the last two gate. Just about similar volume in the 1,2 and 3,4 gates are connected in parallel with the similar distances from the sprue correspondingly. Experiment 10 and 11 shows same volumetric flow. Similar time to reach the 1,2 and 3,4 gate which indicates that due to the certain condition, the length of the runner which is the main answerable for the minor deviation in seconds, the velocity is increased in due to rest of the gates closed conduction.

The Table. II describes the discharge of center sprue parallel connection and center sprue runner extension parallel connection order as display in Fig. 3. The data from first experiment has even volumetric flow with time to incur their gates vary in minor level. It shows the eliminating of frictional flow, the material is non uniform all over the cavity.

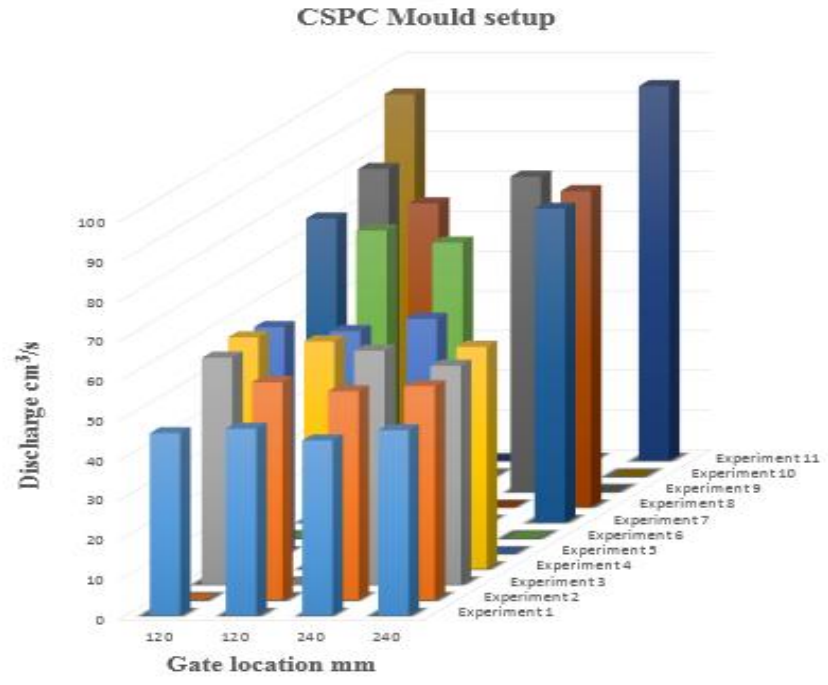

Fig. 4. Discharge chart of side spure order (CSPC). CS-RE-PC Mould setup

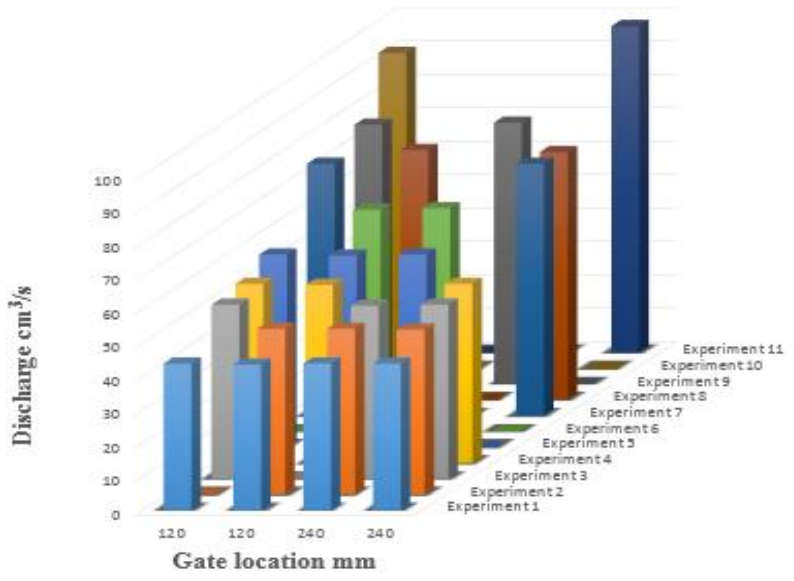

Fig. 5. Discharge chart of center pure runner extension order (CS-RE-PC).

The even flow exist in the prior set-up of CSPC order. The flow of CS-RE-PC order where the sprue and the gates of both sides distance is same. The supply of the water is uniform throughout the cavity. Table. II displays the discharge water flow via all four gates, closing the 2 gates and 3 gates as per the prior Table. I. The discharge of the CSPC and the CS-RE-PC are compared in the table II. Table II shown the water flow through the gates in first reading and its discharge withal the entire gate in the CP-RE-PC as matched to the CSPC set-up. The further data of ascent discharge by shutting one of the gates in the parallel gate with a slight changes in the remaining gates in experiment number 2 and 4.

The result of 1,2 and 3 experiment shows in Fig.4 that the highest and lowest discharge in farthest and nearest gate. The outcome of 1,2 and 3 experiment show in Fig.5, that the last discharge level is the same in all gates, so superior quality of casting use this kind of mould setup.

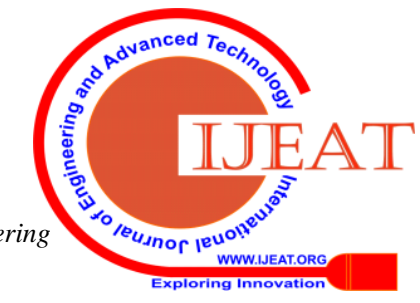




\section{Observation of Flow and Discharge through Multi Gating System}

\section{CONCLUSION}

Appraisement of optimum runner, metal reduction, time management of small scale industries. Area, cross-section and runner a like to the different distance of each gate to spure, in case of four parallel gate system. Previous research of gate was connected serially, spure location and runner cross section was same, leads to maximum velocity deviation. the gate velocity is significant to casting quality. The velocity is constant in all gate leads to relation between casting quality and velocity. Approximately casting quality was 22 to $33 \%$ improved. The usage of gate and runner leads to improve velocity so better quality of casting obtained. The studying of $11 \mathrm{ex}$. of CS-RE-PC has uniform and even flow associating to others, manufacturing of four cavity component comparatively better results coming from CS-RE-PC feeding system. This feeding system estimated by small scale industry, its most effective filling and increasing soundness of casting.

\section{REFERENCE}

1. W. H. Johnson, O. W. Baker and W. S. Pellini, "Principles of gating design: factors influencing molten steel flow from finger gating systems," AFS Transactions, vol. 58, 1950, pp. 661-668,

2. M. J. Berger and C. Locke "A theoretical basis for the design of gates," Foundry, , February 1951, pp. 112-117 and 237-242

3. W. H. Johnson, H. F. Bishop and W. S. Pellini, "Fluid mechanics applied to founding," AFS Transactions, Symposium on Principles of Gating, 1953, pp. 31-39,

4. K. Grube and L. W. Eastwood, "A study of principles of gating”, AFS Transactions, Vol. 58, 1950, pp. 76-107.

5. P. D. Webster, "Computer assisteddesign of horizontal systems for Iron castings,” Foundryman, January 1991, pp. 22-28.

6. R. D. Morales, O. Davila-Maldonado, A. Adams, L. Oliveira, and B. Alquist. "Computer aided filtration modeling of filtration mechanisms in foam filters," AFS Transactions, Vol. 08-122, 2008, pp. 1-17.

7. F. J. Bradley and S. Heinemann, "A hydraulics-based/optimization methodology for gating design”, Applied Mathematical Modeling, 17, 1038, 1993.

8. J. M. Dumaillet and G. M. Wilson, "A configuration of flow modification through foundry filters using both water modeling and simulationsoftware", AFS Transactions, Vol. 02-106, 2002,pp. 187-198

9. I. Rajkumar, N. Rajini, and P. Vasanth, Experimental investigation of flow parameters with the effect of design of multi gating system for casting industries, AIP Conference Proceedings. Vol. 2128. No. 1, 2019.

10. D. S. Richins and W. O. Wetmore, "Fluid mechanics applied to founding," AFS Transactions, Symposium on Principles of Gating, 1951, pp. 1-24.

11. E. Z. Rabinovich, Compt. Rend. (Doclady)Acad. Sci. U.R.S.S., Vol. 54, 1946, pp. 391.

12. J. F. Wallace and E. B. Evans. "Principles of Gating," Foundry, 74-81, October 1959.

13. M. A. A. Khan, \& A. K. Sheikh, Simulation tools in enhancing metal casting productivity and quality: a review. Proceedings of the Institution of Mechanical Engineers, Part B: Journal of Engineering Manufacture, Vol. 230(10), 2016, pp. 1799-1817.

14. K. H. Renukananda, AkashChavan and B. Ravi, "Flow rates in multi-gate systems: experimental and simulation studies," Indian Foundry Journal, vol.5804, 2012, pp. 23-27.

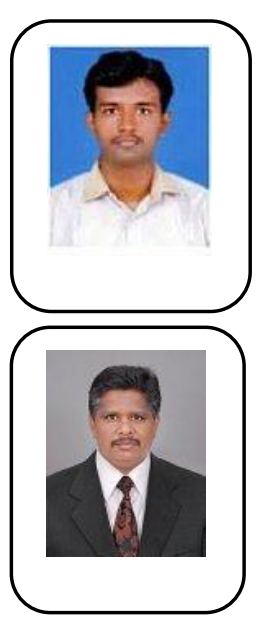

\section{AUTHORS PROFILE}

I.Rakumar, received the Degree in mechanical engineering and master degee in CADCAM, He is a Associate Professor of mechanical engineering, Kalasalinagm Academy of Research and Education, Krishnankoil, Virudhunagar, Tamil Nadu, India. research areas of interest metal casting.

various international journals.

M.Jeeva, is a students of department of Mechanical Engineering, Kalasalinagm Academy of Research and Education, Krishnankoil, Virudhunagar, Tamil Nadu, India.

K.Arunkumar, is a students of department of Mechanical Engineering, Kalasalinagm Academy of Research and Education, Krishnankoil Virudhunagar, Tamil Nadu, India.

P.Kaliraj is a students of department of Mechanical Engineering, Kalasalinagm Academy of Research and Education, Krishnankoil, Virudhunagar, Tamil Nadu, India.

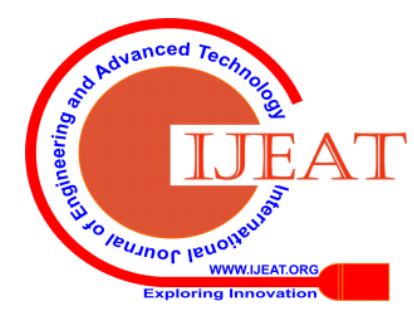

